\title{
Inclusão de recursos tecnológicos digitais nas práticas docentes: uma intervenção pedagógica visando à formação de professores
}

\author{
Inclusion of technological resources in the teaching practices: \\ a pedagoogical intervention aimed at teacher training
}

\author{
Cristina Pureza Duarte Boéssio \\ Doutora em Educação. Professora do Programa de Pós-Graduação em \\ Educação da Universidade Federal do Pampa, Jaguarão, RS - Brasil \\ cristinapdb@hotmail.com \\ Juliana Brandão Machado \\ Doutora em Educação. Professora do Programa de Pós-Graduação em \\ Educação da Universidade Federal do Pampa, Jaguarão, RS - Brasil \\ julianamachado@unipampa.edu.br
}

Tatiane Mena Silveira Melgares Mestra em Educação. Professora da rede municipal e estadual de ensino, Jaguarão, RS - Brasil tatitatimena@gmail.com

Resumo: Este estudo teve como objetivo principal dar dinamicidade ao uso de recursos tecnológicos digitais para qualificar as práticas docentes, por meio de uma intervenção pedagógica desenvolvida em uma escola municipal de ensino básico situada no município de Jaguarão/ RS. A intervenção se deu a partir de encontros de formação, propostos às professoras dos anos iniciais, realizados na escola, durante o ano de 2014. Nesses encontros, as professoras tiveram contato com os recursos tecnológicos digitais durante um determinado período do ano letivo. O procedimento metodológico foi o da proposta da intervenção ancorada em dados qualitativos apontados pelos sujeitos envolvidos diretamente no processo e baseada na metodologia de projetos de intervenção. A coleta de dados foi feita por meio de entrevista. A realização deste trabalho de pesquisa-intervenção favoreceu o contato das professoras com os recursos tecnológicos disponíveis na escola para que pudessem, a partir desse conhecimento, agregá-los às suas práticas docentes.

Palavras-chave: Recursos tecnológicos digitais. Formação de Professores. Intervenção pedagógica.

\begin{abstract}
This study aimed at providing dynamism to the use of digital technological resources to qualify the teaching practice through a pedagogical intervention carried out at a municipal primary school located in the town of Jaguarão/RS. The intervention occurred through training meetings proposed to teachers in the initial years of school, carried out at the school, in the year of 2014. At these meetings, the teachers had contact with the digital technological resources during a determined period along the school year. The methodological procedure was the one of the proposal of intervention based on qualitative data pointed out by the subjects directly involved in the process and based on the methodology of intervention projects. The Data was collected through interviews. This research-intervention work favored the contact of the teachers with the technological resources available at the school so that they could, after acquiring such knowledge, add it to their teaching practices.
\end{abstract}

Keywords:Digital technological resources. Teacher training. Pedagogical Intervention. 


\section{Introdução}

O presente artigo apresenta uma pesquisa-intervenção desenvolvida no curso de Mestrado Profissional em Educação, oferecido pela Universidade Federal do Pampa (UNIPAMPA) Campus Jaguarão/RS. A proposição de uma intervenção pedagógica é o objetivo principal do curso. O projeto de intervenção foi construído a partir das ideias discutidas por Damiani (2013), pois a autora, apud Gil (2010), aponta que:

as pesquisas do tipo intervenção pedagógica são aplicadas, ou seja, têm como finalidade contribuir para a solução de problemas práticos. Elas se opõem às pesquisas básicas, que objetivam ampliar conhecimentos, sem preocupação com seus possíveis benefícios práticos (DAMIANI, 2013 apud GIL, 2010, p. 58).

Tal proposição teve como finalidade principal a inclusão de recursos tecnológicos digitais na gestão das práticas docentes das professoras dos anos iniciais na escola. Essa ideia surgiu a partir da seguinte constatação: as aulas com os anos iniciais ficavam mais atraentes, e os alunos apresentavam-se mais receptivos às propostas pedagógicas nas quais eram incluídos recursos tecnológicos. A partir dessa observação, buscamos autores que discutem a formação continuada de professores e, mais precisamente, a utilização de recursos tecnológicos nas práticas docentes.

A seguir, apresentamos a metodologia utilizada na pesquisa-intervenção, a fundamentação teórica, a análise dos dados obtidos durante o trabalho e as considerações finais.

\section{Metodologia}

A metodologia desta pesquisa foi do tipo intervenção, proposta por Damiani (2013), que explicita a nossa atuação como pesquisadoras dando um caráter investigativo ao desenvolvimento dessa ação interventiva. Nesse sentido, utilizamos instrumentos de coleta de dados que auxiliaram a realização da intervenção na escola em que aconteceram os encontros de formação de 
professores. O primeiro instrumento foi a entrevista semiestruturada com a qual buscamos saber quais eram as dificuldades e necessidades das professoras em relação às tecnologias digitais, já que poderiam estar presentes em suas práticas na sala de aula. O segundo instrumento de coleta de dados foi o questionário, elaborado com questões objetivas de múltipla escolha e versando sobre o uso de recursos tecnológicos digitais.

É importante destacar o contexto no qual aconteceu a intervenção. No ano de 2014, a escola contava com cerca de 160 alunos, 24 professores e três funcionários. No turno da manhã, havia cinco turmas (do $6^{\circ}$ ao $9^{\circ}$ ano). Na parte da tarde, seis turmas, desde a Educação Infantil até o $5^{\circ}$ ano. Atualmente a escola mantém essas mesmas características quantitativas em relação aos recursos humanos.

A equipe diretiva era composta pela diretora, vice-diretora, supervisora e duas orientadoras educacionais. Cerca de 50\% dos professores com o curso de licenciatura plena, e o restante com cursos de licenciatura, além de especializações em áreas afins. Para esse grupo de professores foram proporcionados encontros de formação nos quais foram abordadas as seguintes temáticas: uso do projetor de imagens, vídeos da internet, jogos disponíveis no sistema Linux do laboratório de informática da escola (jogos de alfabetização e de matemática), trabalho com imagens, sites de pesquisa na internet e sugestões para trabalho com as redes sociais.

\section{Tecnologia e práticas docentes na escola}

Para colocar em prática possíveis estratégias que poderiam contribuir com o trabalho docente, fizemos um diálogo com autores que discutem a temática da inclusão da tecnologia nas práticas escolares, a fim de relacionar o objetivo principal dessa intervenção com a teoria propriamente dita.

Consideramos, também, a relevância de trazer os conceitos de tecnologia ao longo da pesquisa. Inicialmente, assumimos a ideia de Kenski (2011, p. 25), segunda a qual "o conceito de tecnologias é variável e contextual. [...]. O critério para a identificação de novas tecnologias pode ser visto pela sua natureza técnica e pelas estratégias de apropriação e de uso".

Nesse caso, compreendemos que Kenski (2011) aponta para a ideia de que a definição do termo tecnologia pode modificar-se de acordo com o contexto no 
qual se encontra e pode, também, gerar novos conhecimentos de acordo com a forma pela qual é usado, ou seja, de acordo com a sua operacionalização. Tal concepção nos induziu a refletir sobre a presença de recursos tecnológicos digitais na escola, os quais, se não provocarem mudanças no sistema de ensino, não passarão apenas de invenções colocadas no espaço escolar sem uma finalidade clara e dinâmica.

Perante os recursos tecnológicos digitais que utilizamos diariamente, como o celular, o smartphone, o computador, por exemplo, nota-se que a sociedade está se direcionando para caminhos diferentes que levam a um maior conhecimento e, assim, desenvolvendo novas teorias sobre o aprender. A contemporaneidade está profundamente marcada pela experiência da virtualidade, que reitera os princípios da sociedade em rede, com alterações nas vivências do tempo e do espaço, estabelecendo uma nova cultura, a cibercultura, vinculada à ideia de conexão (CASTELLS, 1999; LEVY, 2007). A rede é o conjunto de nós que nos interliga, e se faz presente no cotidiano: as várias formas de nos comunicarmos, as instituições bancárias, ou as próprias matrículas para o ingresso no ensino público estadual e também nas universidades, por exemplo. Diante disso, a escola não deveria ficar indiferente a essa realidade, já que o currículo precisa estar ligado à vida dos alunos, fazendo sentido e estando contextualizado efetivamente, pois, como afirma Demo (2008, p.29),

[...] enquanto a escola persiste em manter sua linguagem arcaica, as novas tecnologias assomam com novos textos digitais, mais animados, coloridos, plásticos, interativos (DEMO, 2007b). Para as crianças que sabem lidar bem com o computador em casa, a escola é a própria chatice, principalmente porque não conseguem perceber em suas vidas a importância do que se faz nela.

De acordo com o autor, a escola ainda é permeada por práticas docentes que funcionam com recursos usados há muito tempo como, por exemplo, o quadro, o livro didático e os materiais escolares mais simples, lápis e caderno. Isso não quer dizer que tais instrumentos não tenham mais validade. Atualmente, porém, o autor observa que as crianças têm contato com outros que ultrapassaram aqueles do século passado. Essa mesma ideia é corroborada por Sibilia (2012, p.67), quando sinaliza que os 
dados desse tipo são divulgados e comentados quase que diariamente na imprensa, temperados por cifras assustadoras que ilustram o "fracasso educacional" contemporâneo, sugerindo que o instrumental escolar se encontraria em decadência, não só por haver perdido a eficácia no cumprimento de suas metas específicas, mas também por ter cada vez menos sentido para boa parte de sua clientela.

Diante disso, a escola torna-se sem atrativos para os alunos, os quais, mesmo com pouco acesso aos dispositivos móveis, têm televisão em casa; os pais possuem smartphones ou frequentam lan houses, como acontece com os estudantes da comunidade na qual realizamos a intervenção. Torna-se necessário, então, uma postura pedagógica que procure contemplar o uso de tais recursos no cotidiano de sala de aula, colaborando com os processos de ensino e de aprendizagem.

Conforme Moran (2007, p.7), “a escola, principalmente a partir da $5^{\circ}$ série, fica fragmentada, compartimentada. As disciplinas estão soltas, falam de assuntos sem ligação direta com a vida do aluno. Muitos professores estão desmotivados”. É possível perceber que esse afastamento surge no momento em que o professor planeja suas aulas desconectadas da realidade. Melhoraria sua prática desenvolvendo, em sala de aula, atividades que podem ser trabalhadas através do uso do computador, presente na escola, tanto nos laboratórios de informática como através do netbook que os alunos da rede estadual, no caso do Rio Grande do Sul, dispõem atualmente, já que, como afirma Braga (2013), chegam à escola com outras habilidades para desenvolverem-se cognitivamente, por exemplo.

Segundo Braga (2013, p. 58), "o aluno também mudou e hoje ele traz para a escola novos tipos de habilidades leitoras e produtoras que foram desenvolvidas fora do controle escolar". É possível perceber que a previsão da autora já é uma realidade, visto que os diversos tipos de recursos tecnológicos estão presentes no cotidiano das crianças de várias classes sociais. Partindo da ideia de que a educação fundamental deve ser aquela que ofereça um desenvolvimento integral, não há como ignorar a tecnologia - que está disponível na escola para alunos e professores. As ideias de Demo (2008), que sinalizam sobre as práticas docentes articuladas com recursos restritos aos antigos materiais didáticos e que não fazem parte da realidade do aluno, acordam com o pensamento de Moran (2007), que aborda a questão do ensino composto por disciplinas fragmentadas, e também 
vão ao encontro do que aponta Braga (2013), sobre as novas aptidões leitoras dos alunos de diferentes grupos sociais. Para complementar Braga e Moran, trazemos as ideias de Grinspun (2009, p.44), quando afirma que:

a utilização das tecnologias com sua dimensão interativa mostra que a educação tem que mudar para que o indivíduo não venha a sofrer com lacunas que deixaram de ser preenchidas porque a educação só estava preocupada com um currículo rígido voltado para saberes e conhecimentos aprovados por um programa oficial.

Para colocar, efetivamente, em prática essas sugestões, ponderamos que se faz necessária a formação do docente com essa finalidade, bem como a própria troca de experiências entre os professores sobre os recursos tecnológicos disponíveis na escola e por eles utilizados nas suas práticas. Assim sendo, não basta que as instituições de ensino disponham de recursos tecnológicos, como laboratórios de informática modernos, computadores portáteis, lousas digitais, se o professor não possuir o preparo para aplicar esses recursos em sala de aula. Pensamos que seja importante que a escola, de forma geral, incorpore a ideia de utilizar tecnologia digital nos processos de ensino e de aprendizagem. Leite e Sampaio (2004, p.72) advertem: "para que a escola não perca seu significado e lugar social, não se pode, portanto, continuar ignorando a questão da tecnologia na formação do professor".

Nesse sentido, um dos agravantes em relação ao uso dos recursos tecnológicos nas práticas pedagógicas é o fato de os professores não obterem o preparo técnico e pedagógico necessário para usá-los de forma significativa, ou seja, o acesso a eles existe, o que falta é qualificar o docente. Entendemos, na mesma perspectiva de Demo (2008), que a escola, no momento atual, carece de professores que reconheçam o avanço tecnológico no que se refere às novas formas de comunicação, por exemplo. Segundo esse autor, "torna-se urgente procurar alternativas para além da atual rotina escolar". (DEMO, 2008, p.5). Isso significa ser imprescindível que os professores pensem a possibilidade desse avanço ser um caminho sem retorno e consigam trabalhar a sua capacidade crítica para com os recursos tecnológicos tão presentes no seu cotidiano.

A escola não deve ignorar as tecnologias, ou entrar em conflito com elas, pois, assim, estará usando uma linguagem muito distante dos jovens, deixando 
de ser um espaço social e afastando esse jovem cada vez mais do espaço escolar, tornando-o um fator de desigualdade, dentre tantos discutidos contemporaneamente. Já o professor precisa assumir o papel de mediador entre o aluno e a tecnologia, como uma forma de aproximá-lo da escola através desses recursos que, conforme Kenski (2011), são "baseados no uso da linguagem oral, da escrita e da síntese entre som, imagem e movimentos, o processo de produção e o uso desses meios compreendem tecnologias específicas de informação e comunicação,[...]" (2011, p. 28). A seguir passamos a relatar algumas reflexões sobre formação de professores e as tecnologias digitais.

\section{A formação de professores para o uso das tecnologias digitais na escola}

Assumindo a ideia já defendida de que os professores precisam de formação técnica e pedagógica para incluir em suas práticas pedagógicas os recursos tecnológicos digitais, consideramos relevante tematizar a formação continuada do professor.

Cabe aqui enfatizar que a percepção de que o professor pode desempenhar o papel de mediador diante dos recursos tecnológicos presentes na vida do aluno e na escola desmistifica a ideia de que serão substituídos pelos computadores futuramente. Pensamos que o senso crítico e o exercício de interpretar dados em geral são processos que se desenvolvem na interação entre os indivíduos, ou melhor, na relação professor/aluno. E essas relações podem ser discutidas nos momentos das formações continuadas proporcionadas pela escola e suas mantenedoras. Porém essas formações quase sempre acontecem de forma esporádica e distante do contexto escolar. Na perspectiva de Imbernón (2010, p.40),

atualmente são programados e ministrados muitos cursos de formação, mas também é evidente que há pouca inovação ou, ao menos, essa não é proporcional à formação que existe. Talvez um dos motivos seja o predomínio ainda da forma descontextualizada, distante dos problemas práticos dos professores e de seu contexto, baseada em um professor ideal que tem uma problemática sempre comum, embora que tudo isso não existe. 
Conforme aponta o autor, as formações continuadas deveriam acontecer como algo que prossegue a partir do contexto particular de cada situação, ou seja, cada escola possui suas peculiaridades e dificuldades a serem atendidas, por isso poderiam ser planejadas e pensadas a partir das necessidades de cada contexto escolar. Desse modo, a realidade escolar pensada a partir das práticas docentes nela inseridas, seria o ponto de partida para planejar e pensar em formações continuadas de professores bem como em programas de formação docente, tão importantes no espaço escolar. Ainda segundo Imbernón (2010, p.47), "a formação distante da prática docente deveria ser reduzida. Nessa formação, os aspectos quantitativos são mais valorizados que os qualitativos [. . .]". Na mesma perspectiva, quanto aos programas de formação docente, Garbin (2014, p.38-39) argumenta que:

trata-se, muitas vezes, de programas criados de maneira distante da realidade escolar, o que pode desencadear uma resistência, por parte dos professores, aos saberes que são produzidos pela universidade. Ao julgarem que os conhecimentos acadêmicos pouco ou nada contribuem para o seu trabalho docente diário, os professores rejeitam as propostas didáticas, curriculares e teóricas que recebem da comunidade acadêmica.

Assim, entendemos que os autores não descartam a formação que incentive o professor a buscar e conhecer novas teorias para considerá-las, ou não, como um conhecimento novo, mas sugere que a formação potencialize o que já está posto como uma necessidade, em cada contexto escolar. Dessa forma, tornarse-ia válido e motivador o professor ter a oportunidade de dar seguimento ao seu processo de formação continuada, enquanto docente, do que apenas fundamentar, acumular e abordar novas teorias que poderão, ou não, fazer a diferença na sua prática cotidiana na escola.

A formação continuada de professores poderia ser percebida, por quem as organiza, como um ponto de chegada, já que poderá ter melhor efeito se partir da motivação do professor e não, por exemplo, de algo imposto e programado para apenas uma semana de cursos de formação. Geralmente é assim que as mantenedoras das escolas planejam os cursos para os professores. Porém, é razoável concordarmos que a motivação é algo que surge de dentro para fora, que parte 
do sujeito a partir de uma necessidade. Cortella (2014) afirma que "não é possível motivar alguém, mas pode-se estimulá-lo para que ele se motive. E, portanto, que ele mesmo abra essa porta" (2014, p.71). Assim, diante da perspectiva de o professor estar motivado para aderir à formação continuada, reiteramos que essas formações devem ser pensadas a partir dos sujeitos que dela vão usufruir, pois, no caso do uso das tecnologias digitais, por exemplo, é importante ressaltar que os professores, em sua maioria, não são nativos digitais.

Demo (2008, p.40) diz que:

[. . . ] o problema mais agudo é que traduzimos na formação permanente os mesmos vícios da original, encurtando os cursos a alguns dias ou menos, em ambiente marcantemente instrucionista. As regras são as "semanas pedagógicas", que dificilmente duram uma semana e se organizam em torno de palestras ou coisas similares. [...] Oferecem-se aos professores tais eventos na expectativa de que isso repercuta na aprendizagem escolar. Na prática os professores retornam da semana pedagógica, tudo na escola continua como antes, principalmente continua a mesma aula.

A ideia do autor reforça a nossa intenção de ter oferecido aos docentes formações que foram acontecendo durante um período ano letivo de 2014 para, assim, transcorrerem como um processo de formação, e não apenas como uma proposta descolada da prática pedagógica. Além dos temas terem sido pensados a partir da fala dos professores em entrevista e questionário por eles respondidos, nos encontros de formação houve a interação dos docentes com os recursos tecnológicos digitais elementares, disponíveis na escola.

\section{A formação de professores na escola: apresentação e análise dos dados obtidos na intervenção}

A ideia de proporcionar encontros de formação das professoras dos anos iniciais da Escola Municipal de Ensino Fundamental Dr. Fernando C. Ribas, com os recursos que dispõe ao seu quadro de docentes, foi construída através dos apontamentos e relatos das professoras, obtidos na coleta de dados desta 
pesquisa: "Nas minhas aulas costumo utilizar data show, computador, câmera fotográfica, recursos midiáticos como revistas, jornais, tudo é importante para a aprendizagem dos alunos como forma de material pedagógico" (Professora 3). Este relato sintetiza as falas encontradas no início da formação. A partir dessas informações, selecionamos os seguintes temas: uso do projetor, vídeos da internet, jogos disponíveis no sistema Linux do laboratório de informática da escola (jogos de alfabetização e de matemática), trabalho com imagens, sites de pesquisa na internet, sugestões para trabalho com as redes sociais, trabalho com o Power Point e Impress(Linux).

Primeiramente, vamos comentar os encontros de formação na escola que tiveram como objetivo principal a experimentação técnica de recursos tecnológicos digitais, por parte das professoras, como, por exemplo, a instalação e o uso do projetor, a técnica de salvar vídeos e imagens disponíveis na internet e também algumas orientações sobre pesquisa na web.

Esses momentos, nos quais as professoras experimentaram efetivamente tais ações, salvando vídeos em seus computadores portáteis e observaram a técnica de instalação do projetor de imagens da escola, foram considerados propostas acessíveis de acordo com seus próprios relatos. Todas as professoras pesquisaram pelo menos um vídeo que poderia ser utilizado em sala e o salvaram em seus computadores portáteis, e em seguida, ressaltaram a facilidade da técnica. Essa ideia vai ao encontro de Kenski (2011, p.44), ao considerar que:

Uma vez assimilada a informação sobre a inovação nem a consideramos mais como tecnologia. Ela se incorpora ao nosso universo de conhecimento e habilidades e fizemos uso dela na medida de nossas possibilidades e necessidades.

Durante o período das formações, foi possível, inclusive, registrar algumas aulas das professoras que fizeram uso de vídeos projetados em slides para as suas respectivas turmas de alunos dos anos iniciais. Observamos, então, que esses momentos de efetiva prática dos professores em sala de aula foram ao encontro da proposta de intervenção, sustentada pelas reflexões que aconteceram na escola, e geraram algumas práticas pedagógicas inovadoras.

Desse modo, as professoras experimentavam, de forma prática, as técnicas propostas, para, assim, caracterizar esses momentos como de formação efetiva 
de ações que, até então, lhes pareciam difíceis, como foi colocado por algumas, na entrevista: "Para mim foram ótimas essas formações, pois me proporcionou como trabalhar alguns itens no computador, por exemplo: trabalhando imagens, textos utilizando os efeitos de design, animação e escrita em cima das imagens" (Professora 1).

Dando seguimento às atividades de formação continuada na escola, citamos, a seguir, alguns resultados surgidos a partir de temáticas que visavam a sensibilizar as professoras sobre o uso pedagógico de alguns recursos tecnológicos digitais. Mencionamos, então, os jogos do sistema Linux relacionados à alfabetização e ao raciocínio lógico, o trabalho com imagens e também com as redes sociais, especialmente o Facebook.

É importante relatar que o uso do laboratório de informática da escola foi uma reivindicação da equipe diretiva, relatada em entrevista durante a coleta de dados. Por isso, julgamos que uma forma de responder a essa solicitação seria trabalhar com as professoras os jogos pedagógicos digitais disponíveis nesse laboratório. Para essa iniciativa, ancoramo-nos no que diz Moran (2000, p.98): "os jogos são oferecidos com a finalidade de lazer. Podem vir a permitir a utilização com o uso educacional, se forem integrados a outras atividades propostas pelo professor". Nas Figuras abaixo, apontamos dois exemplos de jogos explorados no sistema Linux: "Simão diz Blinken", que tem como objetivo memorizar sons e cores em um determinada sequência, e "Frações Kbruch", que auxilia na compreensão de cálculo de frações. Uma série de jogos foi explorada, mas estes ilustram as duas áreas que objetivaram ser abordadas na formação para os anos iniciais: alfabetização e raciocínio lógico-matemático.

As professoras experimentaram os jogos sugeridos e foram identificando o objetivo de cada um, assim percebendo o quanto poderiam ser úteis para complementar os conteúdos previstos para suas respectivas turmas. Refletiram, também, sobre a importância de integrá-los à sala de aula para melhorar, inclusive, a questão da concentração dos alunos: "Cada vez mais tenho vontade de incluir trabalhos no laboratório, pois como já falei algumas vezes, é um recurso muito significativo para a aprendizagem" (Professora 4). Tal reflexão vai ao encontro da ideia de Kenski (2011, p. 126) quando aponta: "os jogos desenvolvem habilidades e raciocínios, considerados valiosos em determinados tipos de ações profissionais: o primeiro espírito de equipe, estratégias[...]”. 
No encontro de formação em que as professoras trabalharam e experimentaram a ferramenta Impress do sistema Linux (Figura 4), foi possível perceber que as docentes demonstraram maior facilidade em usar o recurso. Este recurso é similar ao Power Point (disponível no sistema Windows). O objetivo principal é criar apresentações de slides com efeitos no texto, imagens e na própria apresentação. Após a formação, foram feitos alguns registros de trabalhos desenvolvidos em sala de aula como Impress, através da apresentação de pesquisas dos alunos sobre, por exemplo, os pontos turísticos da cidade de Jaguarão, capturados em fotos antigas e atuais.

Como mencionamos acima, após as formações as professoras foram encorajadas a construir e registrar práticas pedagógicas com recursos tecnológicos digitais em suas aulas. A primeira professora, responsável pela turma do $3^{\circ}$ ano, organizou uma apresentação de slides utilizando fotos que os alunos fizeram sobre os pontos turísticos da cidade de Jaguarão/RS (Figuras 5 e 6).

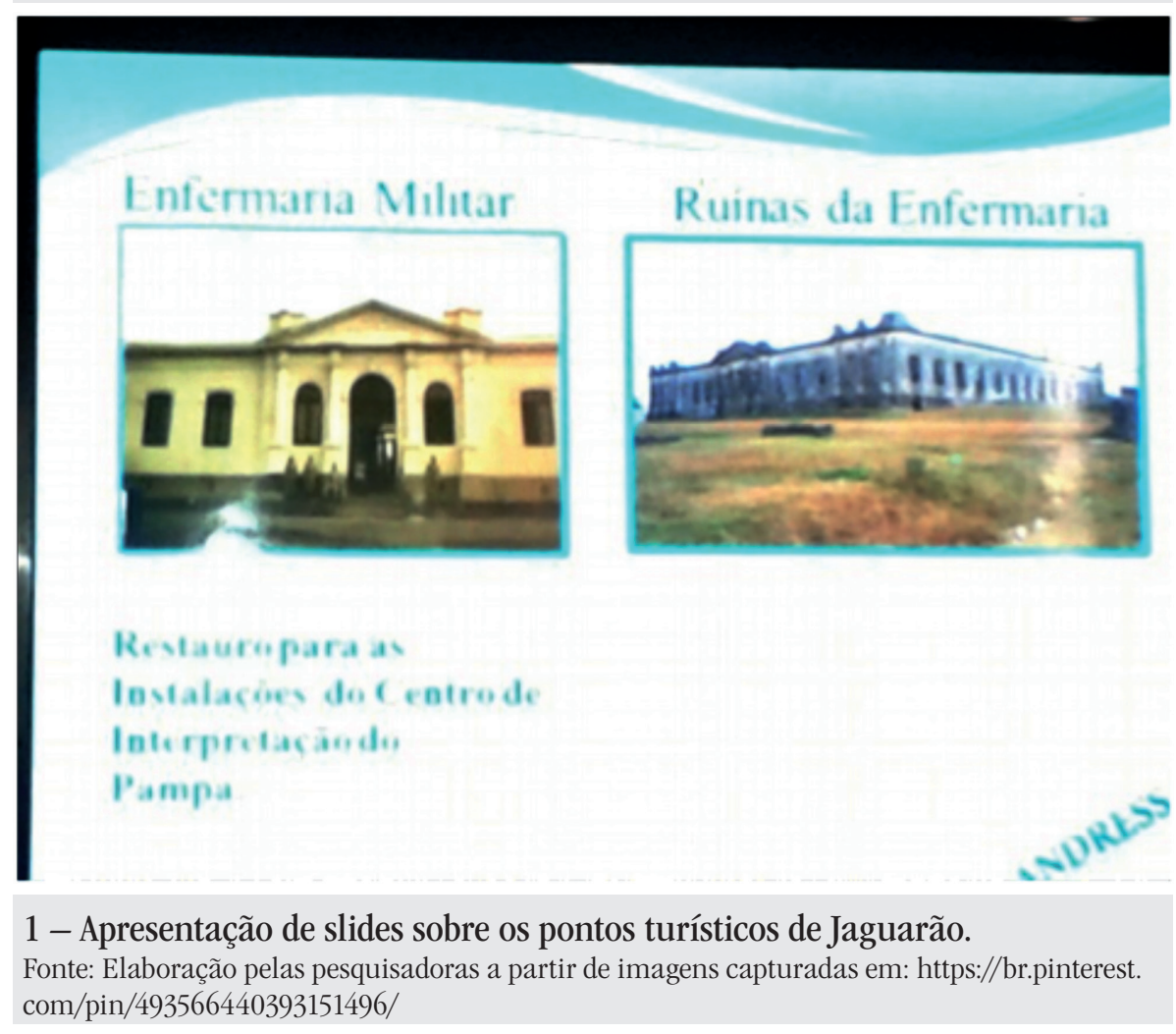


A segunda professora organizou a Hora do conto através de um vídeo de uma história infantil com a turma dos alunos do $1^{\circ}$ ano do ensino fundamental.

As práticas pedagógicas destacadas, bem como as falas das professoras e o relato das formações, apontam a ideia de que a formação continuada de professores para o uso dos recursos tecnológicos digitais oportuniza a reconstrução dos saberes docentes. Assim, o relato desta experiência conduz à reflexão de que é fundamental constituirmos o espaço escolar de momentos como estes. Dessa maneira, proporcionaremos espaços formativos na escola que vão ao encontro do que enfatiza Imbernón (2010, p.73): "é de grande importância o desenvolvimento do aspecto humano e grupal dos professores, no sentido de se desenvolverem processos atitudinais colaborativos e relacionais como parte do processo profissional". A seguir, apresentaremos as considerações finais, que nos possibilitam refletir sobre futuras formações continuadas nos espaços escolares.

\section{Considerações Finais}

Ao analisarmos o objetivo geral deste trabalho, de qualificar as práticas docentes através do uso dos recursos tecnológicos digitais, percebemos a dinamicidade ocorrida durante os encontros que tiveram características de oficina e, também, de forma discreta, nas práticas de algumas professoras. Assim, é possível observar o quanto se faz importante a formação docente dentro da escola, destacando os espaços proporcionados aos professores para a contínua formação que ocorreu concomitantemente às suas práticas.

Ao longo da intervenção, observamos o envolvimento das professoras com cada tema proposto para os encontros e, também, a participação efetiva do grupo. Como consequência dessa integração, houve um movimento das professoras dos anos iniciais da escola, que passaram a ver o uso dos recursos tecnológicos digitais de forma positiva, talvez pelo fato de perceberem que não é tão difícil aliálos às suas práticas, pois algumas já utilizam, em sala da aula, o conhecimento adquirido nas formações. Percebemos que essa atitude vai ao encontro da ideia de que o professor, como gestor da sua prática, é quem pode deliberar a utilidade da tecnologia que a escola dispõe, buscando, assim, meios de melhorar os processos de ensino e aprendizagem. Diante dessa ideia, acreditamos que incluir a tecnologia na escola, considerando a questão da formação continuada de professores e 
das práticas docentes, traz um sentido para a presença desses recursos no contexto escolar. É possível avaliar que a questão da tecnologia nas práticas docentes ainda é um desafio para os professores e precisa ser frequentemente trabalhada e discutida nas escolas.

Ainda, referindo-nos aos encontros de formação, destacamos as reflexões e circulação de novas práticas docentes que poderão ser incorporadas à escola, desencadeando, assim, uma perspectiva de mudança. A partir da proposta desta pesquisa, acreditamos ter proporcionado um espaço para a discussão do tema, e, a partir dela, esperamos, também, ter conseguido contribuir, mesmo que de forma inicial, com o uso das TIC nos processos de ensino e de aprendizagem dos alunos e com a formação dos professores. Ao desenvolver a pesquisa-intervenção, além de pensar nos impactos internos à instituição em que foi realizada, é fundamental a reflexão que possibilita discutir e problematizar tais práticas como alternativas à formação de professores e à qualidade do processo pedagógico em geral. Nesse sentido, afirmamos como fundamental a formação docente em serviço para o uso de recursos tecnológicos digitais no cotidiano na escola, contribuindo para o estabelecimento de novas práticas e relações na rede.

\section{Referências}

BRAGA, Denise Bértoli. Ambientes digitais: reflexões teóricas e práticas. 1.ed. - São Paulo : Cortez, 2013.

CASTELLS, Manuel. A sociedade em rede. São Paulo: Paz e Terra, 1999.

CORTELLA, Mario Sergio. Educação, escola e docência: novos tempos, novas atitudes. São Paulo: Cortez, 2014.

DAMIANI, Magda Floriana; et. al. Discutindo pesquisas do tipo intervenção pedagógica.In. Cadernos de Educação. UFPel- Pelotas [45], 57 - 67, maio/ago. 2013. 90

DEMO, Pedro. Aprender bem/mal. Campinas: Autores associados, 2008.

GARBIN, Mônica Cristina. Et. Al. A colaboração na formação continuada de professores: 0 projeto M-Learning. In. Revista Ibero-americada de educação. $\mathrm{N}^{\circ}$ 65, 2014.

GRINSPUN, Miriam P.S. Zippin (Org.). Educação tecnológica: desafios e perspectivas. 3. ed., rev. e ampl. São Paulo: Cortez, 2009.

IMBERNÓN, Francisco. Formação continuada de professores. Tradução de Juliana dos Santos Padilha. Porto Alegre: Artmed, 2010. 
KENSKI, Vani Moreira. Educação e Tecnologias: o novo ritmo da informação. 8. ed. Campinas: Papirus, 2011.

LEITE, Lígia Silva; SAMPAIO, Marisa Narciso. Alfabetização tecnológica do professor. Petrópolis: Ed.Vozes, 2004.

LÉVY, Pierre. Cibercultura. São Paulo: Ed.34, 2007.

MORAN, José Manuel. A educação que desejamos: novos desafios e como chegar lá. Campinas: Papirus, 2007.

MORAN, José Manuel. Novas tecnologias e mediação pedagógica. Campinas: Papirus, 2000.

SIBILIA, Paula. Redes ou paredes: a escola em tempos de dispersão. Tradução Vera Ribeiro. Rio de janeiro: Contraponto, 2012.

recebido em 31 ago. 2017 / aprovado em 31 jan. 2018

Para referenciar este texto:

BOÉSSIO, C. P. D.; MACHADO, J. B.; MELGARES, T. M. S. Inclusão de recursos tecnológicos digitais nas práticas docentes: uma intervenção pedagógica visando à formação de professores. Dialogia, São Paulo, n. 29, p. 153-167, mai./ago. 2018. Disponível em: <https://doi.org/10.5585/Dialogia.n29.7779>. 
